Running Head: BOUNDED AGENCY OF YOUNG ADULTS

Concepts of Bounded Agency in Education, Work, and the Personal Lives of Young Adults

\title{
Karen Evans
}

Institute of Education, University of London, UK

Corresponding author:

Karen Evans

School of Lifelong Learning and International Development

Institute of Education

University of London

20 Bedford Way

London

WC1H 0AL

UK

Phone: 00442076126561

Fax: 00442076126632

Email: k.evans@ioe.ac.uk 


\begin{abstract}
This paper traces the development of a series of Anglo-German studies on how young adults experience control and exercise personal agency as they pass through periods of transition in education and training, work, unemployment and in their personal lives. The overarching aim has been to develop an extended dialogue between ideas and evidence to explore the beliefs and actions associated with life-chances under differing structural and cultural conditions. What kinds of beliefs and perspectives do people have on their future possibilities? How far do they feel in control of their lives? How does what people believe is possible for them (their personal horizons developed within cultural and structural influences) determine their behaviours and what they perceive to be 'choices'? This research contributes to the reconceptualisation of agency as a process in which past habits and routines are contextualised and future possibilities envisaged with in the contingencies of the present moment. The paper concludes by explaining the concept of 'bounded agency' as an alternative to 'structured individualisation' as a way of understanding the experiences of people in changing social landscapes.
\end{abstract}


Concepts of Bounded Agency in Education, Work and the

Personal Lives of Young Adults

Research into the experiences of young people aged between 16 and 25 in comparable cities in England and Germany has been conducted by the author over a twelve year period, in a series of projects supported by the Anglo-German Foundation and the UK Economic and Social Research Council. Findings from these 'empirical encounters' are used here to construct a new, extended dialogue between ideas and evidence (see Ragin, 1991) leading to the concept of bounded agency.

The starting point was a comparative study of the 'transition' experiences of 640 young people from four labour markets (Bremen and Paderborn in Germany, Swindon and Liverpool in England). The trans-national team contrasted the 'accelerated' transitions of England when compared with the 'extended' transitions experienced by young people in West Germany (Evans \& Heinz, 1991). Analyses in these Anglo-German studies generated theoretical constructions concerning the relationship between transition behaviours, as an important part of the young people's personal histories, and career outcomes. This became a core theme for the book Becoming Adults in England and Germany (Evans \& Heinz, 1994). By 'transition behaviour' we mean the patterns of activity people adopt in attempting to realise their personal interests and occupational goals within social requirements and structural opportunities. Transition behaviour may change in the case of failing to achieve the intended result at any stage of the process, and can be linked with career trajectories. For the purpose of this research, we had identified four broad trajectories to satisfy the conditions of comparability between the countries: the academic mainstream leading towards higher education; training and education leading to skilled employment ${ }^{1}$; other forms of education and training leading typically to semi-skilled employment; early labour market experience of unskilled jobs, unemployment and 'remedial' training schemes. 
We found evidence for four transition behaviours, which we labelled strategic, step-bystep, taking chances and wait and see behaviours. These were activity patterns that young people have adopted when moving along trajectories into labour markets. The extent to which young people have succeeded in developing longer-term occupational goals depends not only on their past socialisation in family and school, but also to a large degree on the way their identity formation is linked to challenge and rewarding experience in the passage to employment itself. If a young person embarks on this risky voyage in a clearly defined progression of qualifications, based on his or her decisions, this tends to bring stability to the unfolding life course. If a diffuse, short-term sequence of activities is embarked on in a way that is reactive to immediate job demands and upheavals, the risks are far greater. 'Strategic' and the 'taking chances' approach to transition are expressions of this active kind of individualisation. There is a more passive kind of individualisation in which the young person is carried along in socially accepted transition patterns, without a sense of ultimate goal or overall direction. Transition behaviour which is characterised by a 'step-by-step' or a 'wait and see' pattern is linked to a passive kind of individualisation.

As we showed in Evans and Heinz (1993, 1994), individualised career paths and life plans sometimes cut across trajectories and do not necessarily comply with the expectations of parents or employers. The timing of transition is dependent on the available jobs and cultural norms about transitions, which influence the decisions of young people. In England, parents and young adults often see early transition to an independent employment status as most desirable. Extended vocational training and academic education are also seen in terms of quick accession to the desired occupational status and the economic independence that goes with it. Many young people, especially from working-class backgrounds, meet training schemes which are in 'lieu of work' with reluctance or even distrust, because they are afraid that their expected independence will be curtailed. 
In Germany, we showed that the process of becoming an adult is more protracted, with the duration of vocational education and higher education defining the timing of this transition. The cultural expectations mean that the majority of the young generation serve an apprenticeship or pursue academic studies without the feeling of being socially dependent. They have a socially recognised role as an apprentice or as a student. The minority of young people who are channelled into schemes or casual jobs after leaving school have difficulties in legitimising their social status, because they cannot rely on an institutionalised 'pacing' of their transitions. Thus they are in a situation where transition behaviour may be reduced to 'wait and see'.

The suggestion we put forward, on the basis of our initial research, that the less institutional English framework might encourage reactive transition behaviour, eventually proved to be an over-simplification. 'Step by step' was a frequently found transition behaviour in both countries. In England, 'step by step' was encouraged by the fluid nature of the opportunities available. In Germany 'step by step' was encouraged by the highly structured system which offered alternatives in a longer time-frame for decision-making. In both countries relatively few young people had crystallised their occupational goals. Where they had, proactive strategies were encouraged by the German arrangements that set out regulated pathways and criteria for achieving them. For those with clear occupational goals in England, the ways of achieving them were often less transparent, and 'step by step' was often the response. Risk-taking was also encouraged in both countries, in different ways. Experimentation was possible within the institutionally supported transitions of Germany. In England risk-taking was more likely in the more buoyant labour markets. In both cases, recovery would be possible, by virtue of institutional support in Germany and the operation of the local labour market in England. 
We showed that career outcomes depend not only on the transition behaviours of young people but also on the institutional and labour market settings and social support available. The contrast between the regulated German and unregulated British approaches to young adult transitions found in our 1991 and 1994 studies were maintained through much of the 1990s, and in some respects have become more sharply drawn. A new study of Eastern Germany became possible in the mid-1990s enabling comparisons to be made with Western Germany and England. The ways in which social changes have impacted on individuals' lives were central to the rationale of this new phase of Anglo-German research. The Eastern and Western parts of Germany shared a common culture but operated totally different socio-economic systems. West Germany and Britain had different versions of the same socio-economic system, but different cultural histories. Britain and Eastern Germany have experienced, from different starting points, strong effects of market forces and deregulation of previous systems. The research team investigated young adults' experiences of both smooth and broken transitions in the new Federal States. Continuities and discontinuities were seen through the eyes of key players, including vocational trainers, and placed in context through structural data and reports.

When, in the early 1990s, the economy of the new Federal States underwent radical structural changes the workforce was substantially reduced and the Western 'dual system' was implemented. The research in Eastern Germany, started in 1997, showed that although labour market conditions required 'flexibility' and 'new ways of thinking' from the young people and traditional routes could be transcended successfully, the rules of the game were set by the dual system. Taking this into account the studies focused on (1) the effects of the weakness of the dual system under present financial and economic conditions, (2) directions young people in the new Federal States have taken in order to navigate through new education, training and employment structures, and (3) new transition behaviours into and out of employment with 
regard to career outcomes. Through 24 case studies, backed by survey and structural data, we were able to extend the previous Evans and Heinz analysis.

Where Eastern German young people had experienced most or all of their training since 1990, they showed few differences of perspective from their West German counterparts. In the old Federal States of Western Germany, the labour market was itself changing. Previously participation in 'transitional programmes' had been taken as indications of failure and lack of achievement and often trapped young people into vicious circles and downward spirals from which it was difficult to escape. In the changing labour market of the 1990s these transitions were moving closer to their English counterparts, experienced as interim states from which upward or downward chances can flow. 'Taking chances' was more likely to produce upward movement where safety nets are in place and mistakes are therefore not fatal, or where occupational markets were particularly buoyant (e.g. in some growth areas such as insurance). If the 'taking of chances' was likely to produce a worsened situation through lack of social support or depressed labour market conditions, the 'wait-and-see' behaviours that lead to downward drift started to emerge in the ways identified in some English labour markets in the late 1980s and early 90s.

The eastern German dimension to the research raised the question: "To what extent do more open conditions created by social and economic transformations encourage greater personal agency?" The findings showed that those in 'transitional' positions (which could go upwards or downwards) were more likely to improve their position through active transition behaviours, particularly where backed by family support or personal connections. The combination of 'step-by-step' or 'wait-and-see' behaviour with the taking of chances occurred frequently in the east German context, as the person weighed up the unfamiliar situation before taking the chance, or proceeded cautiously and step-by-step having made the first leap into an improved position. 
Overall, the results support the hypothesis that the conditions after the political changes in the east of Germany encouraged personal agency among young people whose intended career paths were diverted or terminated. Some young people were quick to pick up the 'signals' from the system and market. Active transition behaviours and 'going for it' were perceived as the best ways to maximise opportunity and reduce risks for young people in these already precarious positions, particularly where social support meant that mistakes are unlikely to be irrevocable. The results also showed that the 'open' labour market conditions were not as open as might be expected. The undertaking by the Federal Republic of Germany, as part of the unification deal, that qualifications gained in the East would be recognised in the West, ensured that many of those who were proceeding towards 'qualified and experienced worker' status in growth areas of the primary segment of the labour market had access to additional training and opportunities to continue on their existing trajectory

The group with broken transitions remained cautious about their future prospects, even where they had gained entry to the labour market, reflecting the unstable features of the secondary sector jobs. Young people who were in their teens at the time of the political changes had become focused on coping with the here and now in very practical and concrete ways (cp. Leggewie, 1998, pp. 25-26). Their views generally reflected individuals' present experiences of success, failure, setback and unexpected turnings rather than ideological commitment or particular value positions. Success was often ascribed by young people to luck as well as their own personal characteristics, and failure ascribed both to personal 'weaknesses' and to the problems of being 'only an average person' in a highly competitive economic setting.

The evidence from these Anglo-German studies shows that active transition behaviours are important in overcoming setbacks for those already in precarious situations. Structural factors, however, remain highly significant in the shaping of life chances, and we found with 
Martin Diewald (1999) that the transformations were not such that release of new forms of individual competence led to major reallocations of social position.

A third phase of research, funded by the UK Economic and Social Research Council, provided the opportunity to elaborate the theoretical sketch of individualisation processes started in our earlier work, with reference to the work of social theorists such as Ulrich Beck, Martin Baethge and Anthony Giddens. This research went further than previous studies in extending the age range up to 25, investigating new labour markets and, most importantly, focusing on how young adults experience control and exercise personal agency in the extended and multiple transitions experienced between the ages of 18 and 25.

\section{Method}

All of the studies outlined so far have been 'area studies' in which quantitative survey and qualitative interview data have been interpreted in the light of local labour market and socio-economic features, using holistic approaches combining cases and variables drawn from comparative social science (see Ragin, 1991).

The separate area studies comparing young people in the cities Swindon-Paderborn, Liverpool-Bremen followed by Leipzig laid the foundations for an extended cross-national, area-based survey of young people in the early stages of adult life. The research was organised around two key concepts: agency and control. An expanded concept of agency as a process of social engagement was adopted,

in which past routines are contextualized and future possibilities envisaged within the contingencies of the present moment (Emirbayer \& Mische, 1998). The second and related, concept of 'control' started with the idea of control belief as a personal construct which is linked to environmental influences, and is differentially constructed throughout the life course (Bandura, 1997; Flammer, 1997; Rothbaum,Weisz, \& Snyder 1982). 
The research compared the experiences of 900 young adults (18 - 25 year olds) in higher education, employment or unemployment in the English (Midlands) city of Derby with their peers in Hannover and Leipzig, again using a combination of quantitative survey and qualitative interview methods. These cities were each experiencing fundamental socioeconomic change, and the comparisons were intended to make more visible the relationships between labour market and cultural contexts and people's beliefs in the scope they have to improve their life chances by their own efforts (reflecting agency and feelings of control).

\section{Materials}

Questionnaire survey $(n=900)$ of agentic dimensions of past experiences, present activities and future orientations yielded a data set on which factor analytic techniques were used for data reduction. Principal axis factoring was used for factor extraction, with orthogonal rather than correlated factors chosen (to make the respective factors distinct) and a method of rotation (VARIMAX) that minimized the number of variables having a high loading on a factor. Twelve viable SELF (S), CONTROL (C), AGENCY (A) and FUTURE

(F) factors were identified through an initial factor analysis and scaled into indices:

S (1) sociable/confident

$\mathrm{C}(1)$ fulfilled work life

$\mathrm{C}(2)$ fulfilled personal life

$\mathrm{C}(3)$ believes opportunities open to all

$\mathrm{C}(4)$ believes own weaknesses matter

$\mathrm{C}(5)$ planning not chance

$\mathrm{C}(6)$ believes ability not rewarded

A(1) active career seeking

$A(2)$ unlikely to move - also F(1)

A(3) politically active (group) 
A(4) helping/people career oriented

$\mathrm{F}(2)$ negative view of the future

Profiles of mean scores on self, agency and control indices derived from factor analyses were compared across cities for each of the settings, and across settings for each of the cities $^{2}$ (see for example Behrens \& Evans, 2002; Evans et al 2001). Results that are important for the extended dialogue between ideas and evidence are selectively outlined in the next section.

\section{Results}

Most of the young adults in our samples recognised educational qualifications as being of 'considerable' importance in influencing opportunities in life, relative to other ascribed social characteristics. Figure 1 gives a simplified representation of the results from the DerbyHannover-Leipzig study.

\section{FIGURE 1 ABOUT HERE}

There were strong indications that these young adults generally believed in the idea of a 'meritocracy' and that if you 'failed' in life, this was probably your own fault and down to a lack of effort and determination. The effects of social characteristics such as gender, race and social class were less visible to the groups surveyed in the English city. This is not explained by greater social equality in England, but by differences in perceptions of constraints in these contrasting socio-economic landscapes.

Indicators of personal agency, such as active job seeking and 'trial and error' in the search for work, were more evident in the English labour market, which has been deregulated for longer and where individualised behaviours have been most strongly encouraged or enforced. While the young adults surveyed in Hannover and Leipzig were less proactive in relation to the labour market, they showed higher levels of politically active group behaviours involving activities such as participation in political events and engagement in political dis- 
cussions, all of which indicate a continuing trust in collective, rather than individualised, solutions.

This stage of our research showed, as expected, the unemployed groups scoring lower on the 'positive' self, control, agency and 'views of the future' indices, and higher on the 'negative' dimensions compared with respondents in higher education and in employment. All respondents in the unemployed groups scored low on the factor which reflected the extent to which career relies on interest, long-term goals, choice, and planning, and all reported feelings of little control over their present career situation. The least degree of control was stated by the Leipzig respondents. The respondents from Leipzig and Derby attributed lack of achievement to their own perceived lack of skills and to their own weaknesses, to a greater extent than those in the Hannover group. Derby respondents recorded lower scores on assessments of themselves compared with their counterparts in the two German cities. They felt less often confident, their personal lives were less positive, they doubted more often having good social skills. The data showed three patterns of 'self':

- positive self, lower score on individual attribution of failure (Hannover)

- positive self, higher score on individual attribution of failure (Leipzig)

- less positive self, higher score on individual attribution of failure (Derby).

Independent of their feelings about their own specific situation the young adults in Derby had the greatest belief that opportunities are open to all and that ability will be rewarded. They scored higher on these factors than the respondents in the highly structured German labour market and training system. The research participants from Derby scored highest in active career seeking strategies.

The Derby group differed from the Leipzig group in ascribing failure to the individual even more strongly and the strong belief that opportunities are open to everybody. They scored highest on agency factors. In Hannover individualisation of failure was less manifest 
compared with the two other localities. The respondents saw external influences as being of great importance for an individual's opportunities. They had a critical view of the equality of opportunities, were not convinced that ability will be rewarded and generally scored low on agency factors.

In summary, some strong findings emerge from the comparisons. In the English city, the young adults felt that

- their own weaknesses matter

- chance played the major part in their present situation.

They also scored higher on factors which indicated less positive self image. Their more proactive approach to seeking work, compared to German counterparts, could be because they have to be more individually active to deal with their situation, given the diverse and often confusing array of options before them. The uncertain status of people who were unemployed in the early stages of their adult life and unable to keep abreast of their peers who are in work or establishing homes and families of their own, is reflected in a sense of frustration and in a readiness to buy the message that 'better qualifications' may provide a way out of such predicaments. Among those in employment the experience of having gained a foothold in the labour market was associated with greater feelings of control than was manifest among peers in higher education and unemployment settings.

\section{Discussion}

The findings support the thesis that highly structured environments are associated in people's minds with the idea of reduced scope for individual, proactive effort. In highly structured environments opportunities are open only for those following clearly defined routes. Consequently, it is those same structural opportunities or barriers that are held responsible by individuals for any failure. The English findings suggest that one consequence of an environment that fosters a belief that 'opportunities are open to all' is that people blame 
themselves for their failures in education and the labour market. In the highly structured western German system, external factors can more easily be held responsible for failure, giving people greater scope to develop a positive sense of self in early adult life.

The East German young people, despite placing great weight on external factors which influence an individual's opportunities, often ascribed failure to themselves as individuals. While this finding may be regarded as contradictory and unexpected from the application of general reference group and attribution theory, the fact that this generation had suddenly to invent new 'scripts and routines' for themselves after the political changes and had to evaluate themselves in relation to western norms and expectations may explain these patterns. With their feelings of lack of control and disbelief in equality of opportunities it is not surprising that this group had the most negative view of the future.

One important finding was that young adults were rarely fatalistic. Even among unemployed people, responses suggested frustrated agency rather than fatalistic acceptance of things as they are. The overriding perspective is that the future is in one's own hands, and while setbacks will be encountered, it is down to the individual to find ways to cope and to overcome them.

It was German sociologists who developed the idea that a process of 'individualisation' is taking place in society and in people's lives. Beck $(1992,1998)$ outlined the nature of an emergent 'risk society.' This emphasised the increased uncertainty and unpredictability of the individual's life course. The person learns to 'conceive of him or herself as the centre of action, as the planning office with respect of his/her own biography' (p.135) trying to minimise risk and maximise personal opportunities. Beck believed that individualisation heralded the dissolution of factors traditionally seen as determining many aspects of life in industrialised societies - class culture and consciousness, gender and family roles. In England 
this work was paralleled by Anthony Giddens' more critical accounts of reflexive modernisation (1991, 1998).

More recently, Furlong and Cartmel (1997) and Engel and Strausser (1998) have argued that these accounts of individualisation are misleading. Furlong and Cartmel claim that the social world has only come to be regarded as unpredictable and filled with risks that can only be negotiated on an individual level, while, in fact, structural forces operate as powerfully as ever and the chains of human interdependence remain intact.

A conceptual scheme was developed for further investigation of the individualisation 'thesis' in the context of theories which explain structure and agency in different ways, In this the work of Beck $(1992,1998)$ and Baethge (1989) have been taken as theoretical sketches to be explored, contested and developed. These and other theoretical stances within the dimensions of structure-agency, internal-external control, social reproduction-conversion, are shown in Figure 2.

\section{FIGURE 2 ABOUT HERE}

Theoretical perspectives which consider the inter-relationships between structure and agency can be located in relation to three dimensions. The first dimension is that of social determinism versus individualisation and reflexivity in social biographies. The starting point for the 'individualisation thesis' is usually attributed to Beck's outline of the 'risk society' (1992, 1998) and its manifestation in the uncertain life situations of people. Baethge (1989) took this thesis further by applying it to the situation of youth in industrialised societies and the structural disintegration of social classes or strata into 'individualised' sub-groups, accompanied by the formation of individualistic identities at the expense of collective identity. As proponents of the idea that people are agents actively and individually engaged in the construction of their own biographies, Beck and Baethge are thus positioned close to the base of 
the cube, while Ziehe's concept of 'makeability' with its emphasis on internal control struggling with the effects of social forces, is placed higher on the structure-agency dimension.

The second dimension emphasises internal versus external control processes. Bandura (1997), Elder (1995), Flammer (1997), Rothbaum et al. (1982), Heckhausen and Schulz (1997) and other 'efficacy' researchers have emphasised internal processes of the 'acting individual' in relation to the external environment. There are limitations to personal control in all domains of life. Some aspects of environment and personal circumstances are extremely difficult to change. Others can be overcome by the exercise of initiative and learning. Social psychologists and sociologists who emphasise internal processes of the acting individual alongside reflexivity and individualisation are positioned at the intersection of agency and internal processes. Those who place greater emphasis the external limits on internal processes can be placed at the intersection of structure and external processes in Figure 3.

The third dimension places the focus on social reproduction/conversion, exploring the degree to which social mobility and transformation can be attributed to individual and collective scope for action. The original position of rational choice theorists such as Goldthorpe (1998) has emphasised the overriding importance of analysing the conditions under which actors come to act, from the sociological perspective. Goldthorpe is positioned far along the social reproduction dimension, and close to the middle for control and agency/structure, in his recognition of the interplay of internal and external factors.

Furlong and Cartmel's emphasis on structural determinants, external processes and social reproduction places the 'epistemological fallacy' argument high on structure/agency and towards the back right hand intersection. Bourdieu's (1993) emphasis on social reproduction is also high but emphasises subjectivities of the acting individual and explores agency in relation to 'habitus' and 'field'. 
The exploration of 'individualisation' requires a better understanding of social regularities and individual differences in the agency of individuals. Taking into account the dimensions of Figure 3, it is possible to develop hypotheses about the structuring effects of contexts while focusing on personal and collective experiences of agency, that is, the social regularities within and between setting and area, and the underlying factors which account for these. As Elder (1995) has observed, all social transitions entail risk of losing personal control, with effects dependent on biography and on material and social situation. The empirically grounded concept of bounded agency developed here sees the actors as having a past and imagined future possibilities, which guide and shape actions in the present, together with subjective perceptions of the structures they have to negotiate, the social landscapes which affect how they act. Bounded agency is socially situated agency, influenced but not determined by environments and emphasizing internalized frames of reference as well as external actions. By examining 'bounded agency' the focus moves from 'structured individualisation' onto individuals as actors, without losing the perspective of structuration. Using the three dimensions of Figure 2, Figure 3 shows how 'bounded agency' is positioned in relation to competing theories of agency.

\section{FIGURE 3 ABOUT HERE}

As actors move in social landscapes, spaces open up for action which are not wholly reducible to the effects of social reproduction or underlying structural features. There are some constraints in a 'social landscape' that will be very difficult to move or remove, but others might be reduced through social and educational policies. Societies need to ensure that the greatest demands to 'take control of their lives' do not fall on those who are the least powerfully placed in the 'social landscape' they inhabit. By focusing our attention on how people with agentic beliefs about work and their social environment encounter frustrations in 
acting upon them, the concept of bounded agency provides a powerful intellectual tool that can inform research, practice and policy at an international level. 


\section{References}

Baethge, M. (1989). Individualisation as hope and as disaster. In K. Hurrelmann \& U. Engel (Eds.), The social world of adolescents: International perspectives. New York: de Gruyter.

Bandura, A. (1997). Self-efficacy in changing societies. Cambridge: Cambridge University Press.

Beck, U. (1992). Risk society: Towards a new modernity. London: Sage.

Beck, U. (1998). Democracy without enemies. London: Sage.

Behrens, M., \& Evans, K. (2002). Taking control of their lives? Comparative Education, $38(1), 17-37$.

Bourdieu, P. (1993). Sociology in question. London: Sage.

Diewald, M. (1999). 'Processes of social exclusion and inclusion on the labour market in the transformation of East Germany. In J Bynner \& R. Silbereisen (Eds.), Adversity and challenge in life in the new Germany and England. Hampshire, UK: Macmillan.

Elder, G. H. (1995). Life trajectories in changing societies. In A. Bandura (Eds.), Self-efficacy in changing societies. Cambridge: Cambridge University Press.

Emirbayer, M., \& Mische, M. (1998). What is agency? American Journal of Sociology, 103(4), 962-1023.

Engel, U., \& Strasser, H. (1998). Global risks and social inequality: Critical remarks on the risk society hypothesis. Canadian Journal of Sociology, 23(1), 91-103.

Evans, K., Behrens, M., \& Kaluza, J. (2000). Learning and work in the risk society. Basingstoke: Palgrave Macmillan.

Evans, K., \& Heinz, W.R. (1991). 'Careers and destinations'. In J. Bynner \& K. Roberts (Eds.), Youth and work. Transitions to employment in England and Germany. London: Anglo-German Foundation. 
Evans, K., \& Heinz, W.R. (1993). Studying forms of transition. Comparative Education, 29(2), 145-158.

Evans, K., \& Heinz, W.R. (Eds.) (1994). Becoming adults in England and Germany. London: Anglo-German Foundation.

Evans, K., Behrens, M., Kaluza, J., Rudd, P., \& Woolley, C., (2001). End of award report, youth citizenship and social change programme. Economic and Social Research Council. England: Swindon.

Flammer, A. (1997). Developmental analysis of control beliefs. In A. Bandura (Ed.), Selfefficacy in changing societies. Cambridge: Cambridge University Press.

Furlong, A., \& Cartmel, F. (1997). Young people and social change? Individualisation and risk in late modernity. Buckingham: Open University Press.

Giddens, A. (1991). Modernity and self-identity. Cambridge: Polity Press.

Giddens, A. (1998). The third way: The renewal of social democracy. Cambridge: Polity Press.

Goldthorpe, J. H. (1998). Rational action theory for sociology. British Journal of Sociology, 49(2), 167-192.

Heckhausen, J., \& Schulz, R. (1995). A life-span theory of control. Psychological Review, $102,284-304$.

Ragin, C. C. (1991). The problem of balancing cases with variables in comparative social science, International Journal of Comparative Sociology, 32(1-2), 1-8.

Rothbaum, F. M., Weisz, J. R., \& Snyder S.S. (1982). Changing the world and changing the self: A two process model of perceived control. Journal of Personality and Social Psychology, 42, 5-37.

Ziehe, T. (1996). Zeitvergleiche. Jugend in kulturellen Modernisierungen. Weinheim, Germany: Juventa. 


\section{Footnotes}

${ }^{1}$ Dual system in Germany; work-based training and apprenticeships or further education college learning to vocational qualification in England.

${ }^{2}$ See Evans, Behrens, Kaluza, Rudd \& Woolley (2001) ESRC end of award report, Award L 134251011 Economic and Social Research Council, Swindon. 


\section{Figure Captions}

Figure 1. Number of respondents stating effect on life-chances to be 'very important' Note. $n=900,300$ in each city

Figure 2. Conceptual schema for structure-agency

Figure 3. The theoretical location of bounded agency 


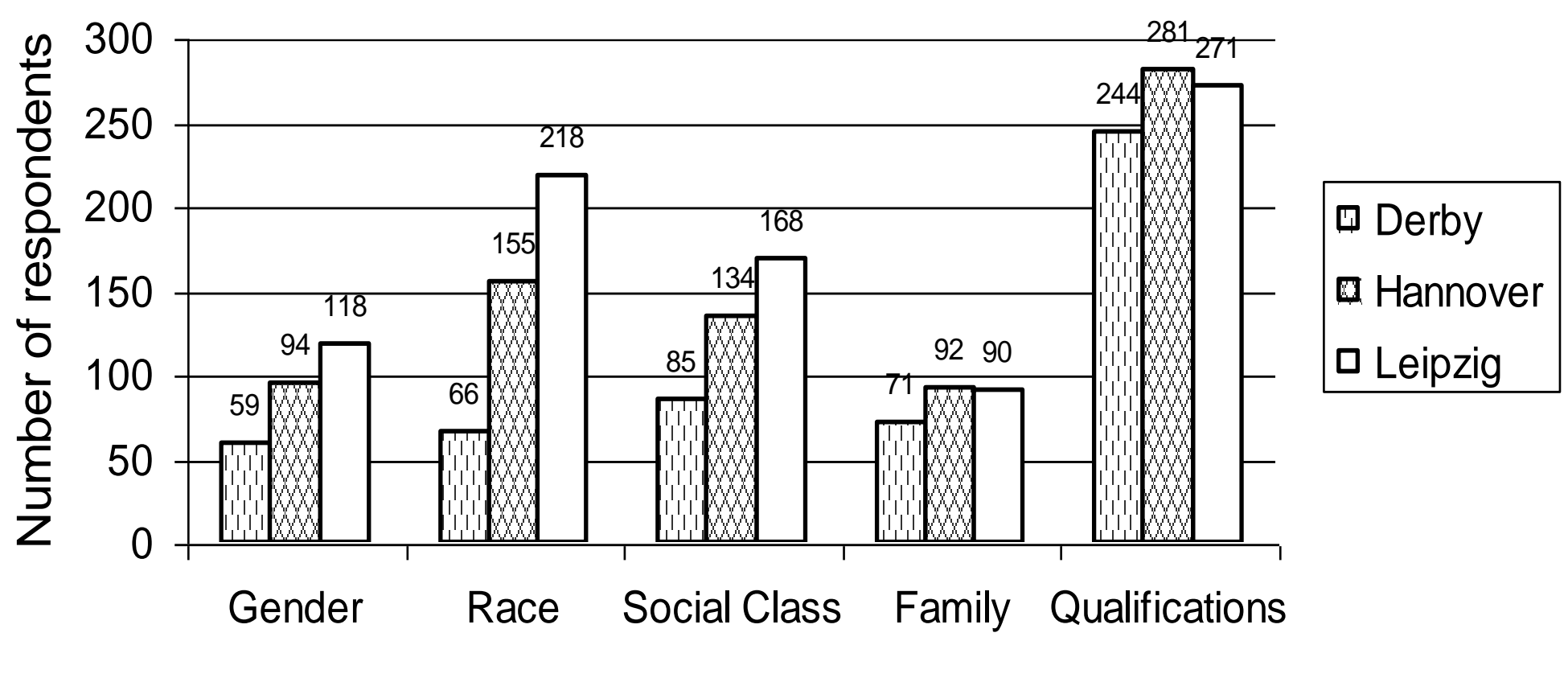




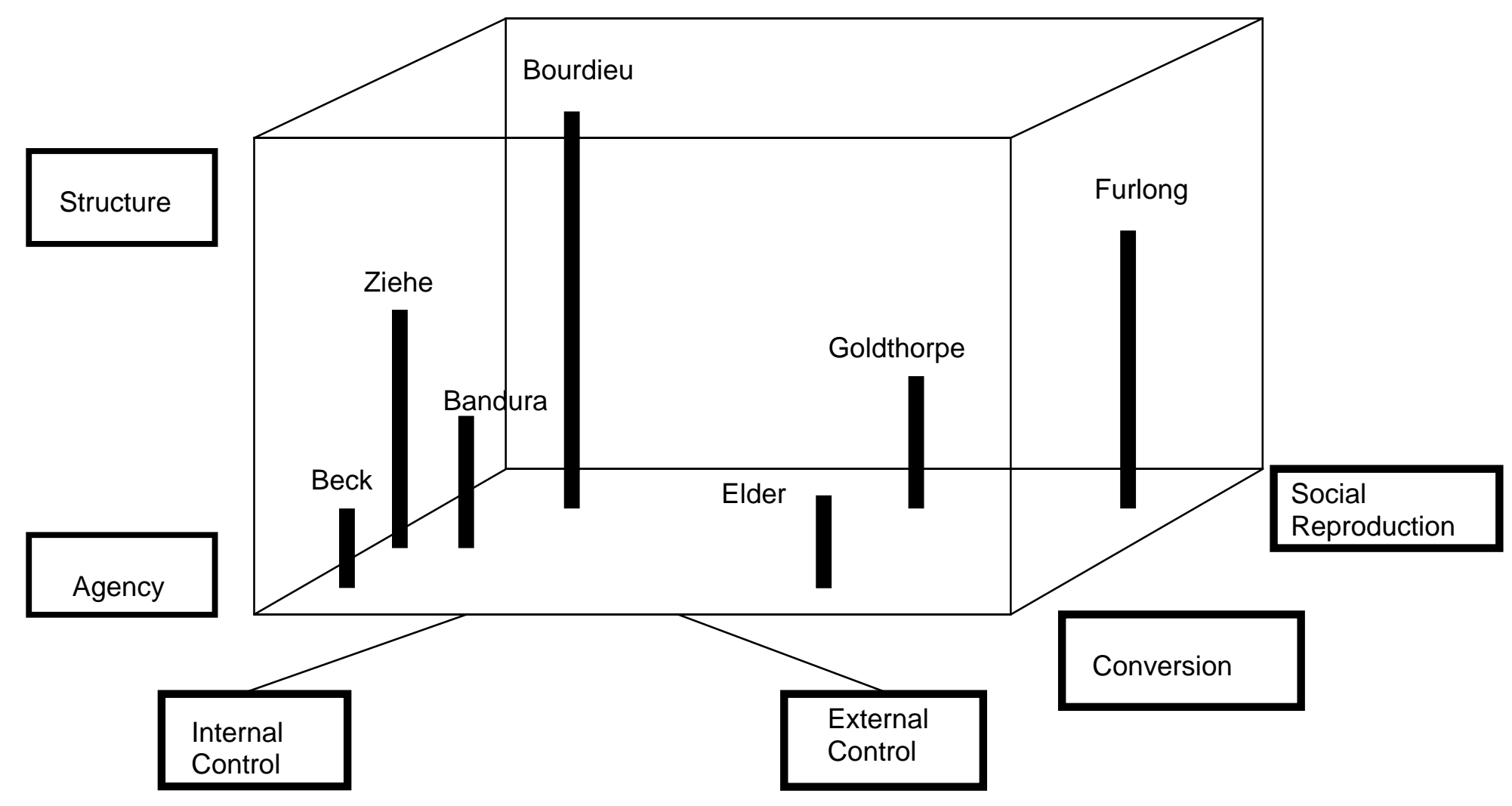




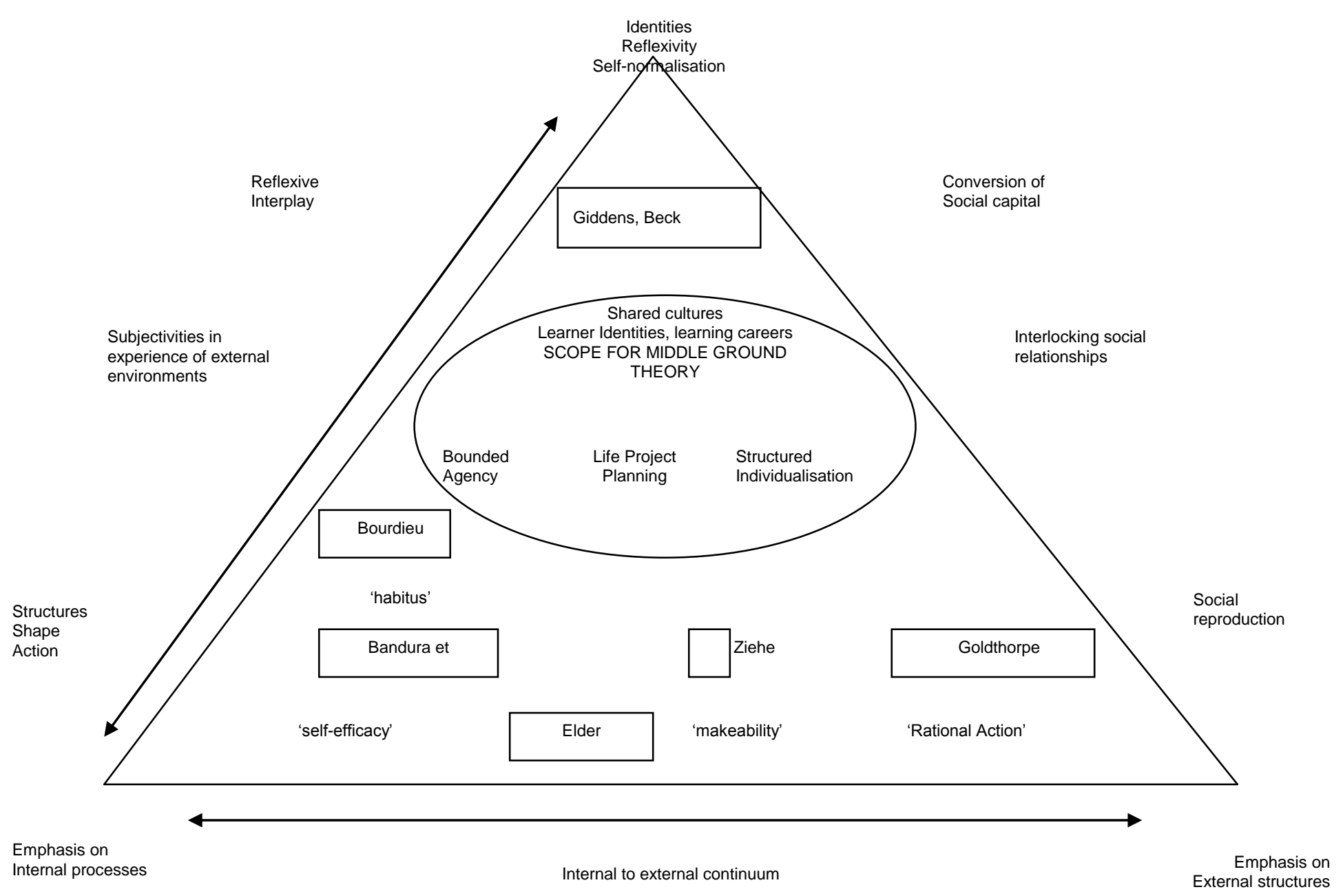

